\title{
Uyarlamalı Bulanık-PI Denetim Esası Dinamik Senkron Kompanzatör ile Reaktif Güç Kompanzasyonu Benzetim Çalış̧ması
}

\author{
Ahmet GANi' ${ }^{1}$, Ö. Fatih KEÇECIOĞLU ${ }^{1}$, Hakan AÇIKGÖZ ${ }^{2}$, Mustafa ŞEKKELi ${ }^{1 *}$ \\ ${ }^{1}$ Kahramanmaraş Sütçü İmam Üniversitesi, Elektrik-Elektronik Mühendisliği, Kahramanmaraş, Türkiye \\ ${ }^{2}$ Kilis 7 Aralık Üniversitesi, Elektrik-Enerji Bölümü, Kilis, Türkiye
}

\begin{abstract}
ÖZET: Elektrik güç sistemlerinde güç katsayısının düzeltilmesi işlemi reaktif güç kompanzasyonu olarak adlandırılmaktadır. Aşırı uyartılması durumunda kapasitif reaktif güç üreten senkron motorlar güç sistemlerinde dinamik kompanzatör olarak kullanılırlar. Senkron motorun hem mekanik güç üreteci hem de güç katsayısı düzeltici olarak kullanılması endüstriyel tesisler için daha ekonomik olmaktadır. Bu durum endüstriyel tesislerin verimini arttırmaktadır. Literatürde reaktif güç kompanzasyonu ile güç sisteminin verimliliğini, kapasitesini ve değişik çalışma koşullarında kararlılı̆̆ını sağlayabilmek için birçok çalışma bulunmaktadır. Bu makale dinamik senkron kompanzatörün denetimi için uyarlamalı bulanık PI denetim yöntemini önermektedir.
\end{abstract}

Anahtar Kelimeler: Reaktif Güç Kompanzasyonu, Senkron Motor, Uyarlamalı Bulanık-PI Denetim

\section{Simulation Study of Reactive Power Compensation with Adaptive Fuzzy -PI Based Dynamic Synchronous Compensator}

\begin{abstract}
The operation of the power factor correction in electrical power systems is called the reactive power compensation. Synchronous motors which generates capacitive reactive power in condition to over excitation are used dynamic compensator in power systems. The use of synchronous motor is more economical for industrial plants both mechanical power generator and power factor corrector. This situation improves the efficiency of industrial plants. In the literature, there are many studies to ensure efficiency, capacity and stability in different operating conditions of power system with reactive power compensation. This paper is proposed adaptive fuzzy PI control method for control of dynamic synchronous compensator.
\end{abstract}

Keywords: Reactive Power Compensation, Synchronous Motor, Fuzzy-PI Control

\section{GİRIŞ}

Teknolojinin gelişmesi ile birlikte son yıllarda endüstride kullanılan endüktif karakterli yüklerle birlikte güç tüketiminde de büyük artışlar olmuştur. Endüktif karakterli yükler şebekeden aktif gücün yanı sıra reaktif güç de çekerler[1].İletim hattından çekilen reaktif güç iletim hattını yükler fakat işe dönüştürülmez[2].Bu nedenle, elektrik güç sistemlerinde şebekeden çekilen reaktif güç kayıplara sebep olur. Meydana gelen kayıplar en aza indirilmelidir. Şebeke kayıplarındaki azalma kablo kesiti ve diğer ölçme, koruma elemanlarının maliyetinin azalmasını sağlayacak ve böylece elektrik güç sistemi daha ekonomik hale gelecektir. Elektrik güç sistemlerinde kayıpları azaltıp sistemi daha ekonomik hale getirmenin tek yolu ise iletim hattının beslediği endüktif yüklerin ihtiyacı olan reaktif gücün, yüke mümkün olan en yakın yerde karşılanmasıdır. Yüklerin ihtiyaç duyduğu reaktif güçler statik olarak kapasitör veya reaktörlerle dinamik olarak ise senkron motorlarla karşılanmaktadır[3-5].Senkron motor ile re aktif güç kompanzasyonu, motorun uyartım akımının değiştirilerek kapasitif veya endüktif karakterde çalışması sağlanarak yapılmaktadır[6].Ayrıca senkron motorun şebekeden çektiği reaktif gücün miktarı da uyartım akımı ile ayarlanabilmektedir. Kompanzasyonu iyi yapılmış bir sistemde, güç katsayısını iyileştirme, en az kayıp ve verimlilik beklenen özelliklerdir [7-9].

$\mathrm{Bu}$ çalışmada reaktif güç kompanzasyonu benzetimi bulanık mantık esaslı PI denetimli senkron motor kullanılarak gerçekleştirilmiştir. Senkron motor; güç katsayısı düzeltme amacıyla kullanıldığında matematik model gerektiren yöntemlerle denetleyici parametrelerinin tespit edilmesinin güç olmasından dolayı bulanık mantık esaslı kompanzasyon denetim sistemi tercih edilmiştir.

\section{REAKTİF GÜÇ KOMPANZASYONU}

Reaktif güç kompanzasyonu elektrik güç sistemlerinde verimi ve kapasiteyi iyileştirmede önemli rol oynamaktadır. Endüktif karakterde güce sahip olan tüketicilerin akım gereksinimi akımın iki bileşeni tarafından karşılanmaktadır. Birincisi işe dönüşen aktif 
akım, ikincisi ise elektrik makinaları ve elektrikli cihazların çalışması için gerekli olan manyetik alanı oluşturan reaktif akımdır. Bu akımlara karşılık gelen güçler,

$\mathrm{S}$ = görünür güç (VA),

$\mathrm{P}=$ Aktif güç $(\mathrm{W})$,

$\mathrm{Q}=$ Reaktif güç (Var) olarak tanımlanırsa

$S=\sqrt{P^{2}+Q^{2}}$

olarak ifade edilmektedir. Bu ifade geometrik olarak şekil 1'deki gibi güç üçgeni ile gösterilmektedir.

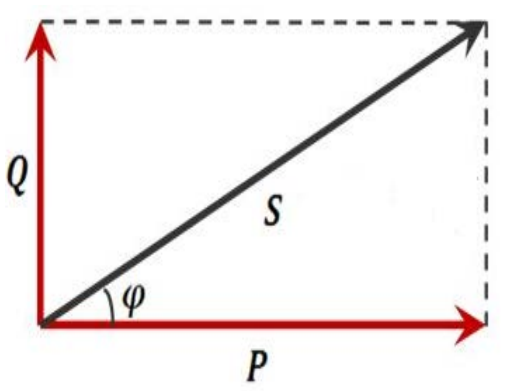

Şekil 1. Güç üçgeni[11].

Burada $\varphi$ faz açısı olarak tanımlanır. Cos $\varphi$ ise güç katsayısıdır. Güç katsayısı aşağıdaki gibi ifade edilmektedir[12].

$\cos \varphi=\frac{P}{S}$

\section{SENKRON MOTOR}

Senkron motor, rotor devir sayısı ile stator döner alanı devir sayısı birbirine eşit olan ve devir sayısı yüklenme durumunda değişmeyen bir alternatif akım motorudur. Senkron motorun uyartım akımı değiştirildiğinde motor şebekeden; omik, endüktif ve kapasitif karakterde akım çekmektedir[13]. Sabit yük ve sabit gerilimde çalışan bir senkron motorun uyartım akımı ile yük akımı arasındaki ilişkiyi veren eğrilere $\mathrm{V}$ eğrileri denir. Aynı şartlarda, yük akımının değişimi ile güç katsayısının değişimi arasında ters orantı bulunmaktadır. Belirli bir yükte en küçük yük akımını oluşturan uyartım akımının bulunduğu nokta, motorun omik çalışma noktası olarak isimlendirilmektedir. Omik çalışma noktasındaki uyartım akımından daha küçük uyartım akımlarında, senkron motor endüktif, omik noktadaki uyartımdan daha büyük uyartım akımlarında ise senkron motor kapasitif olarak çalıșmaktadır. Şekil 2 ve 3'de bir senkron motorda yük akımının ve güç katsayısının uyartım akımı ile değişimini veren eğriler görülmektedir.

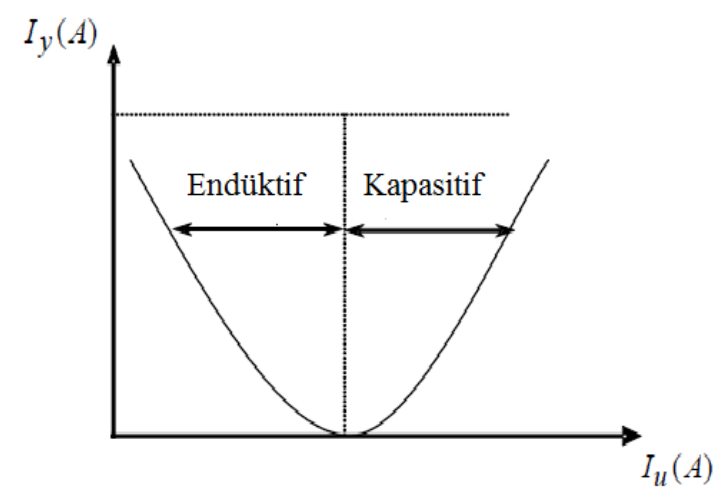

Şekil 2. Yük akımına karşılık uyartım akımı değişimi[14].

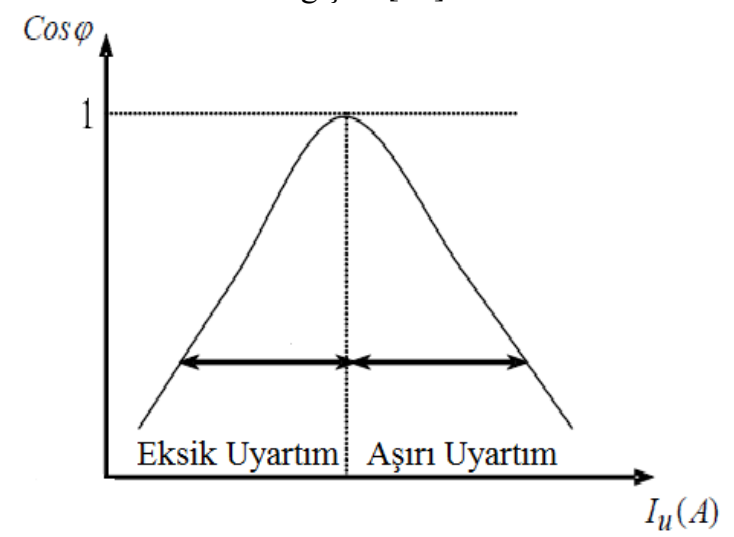

Şekil 3. Güç katsayısına karşılık uyartım akımı değişimi[14].

\section{UYARLAMALI BULANIK DENETIM}

Bulanık mantık, belirsiz durumların anlatımı ve belirsiz olan durumlarla çalışılabilmesi için kurulmuş bir matematik düzen olarak tanımlanmaktadır. Bulanık mantık ile uzman kişinin denetlenecek sistem hakkındaki bilgileri ve öngörüleri denetleyicinin içerisine yerleştirilerek sistem denetlenmektedir. Yani denetlenecek olan sistemin herhangi bir matematiksel modeline ihtiyaç duyulmamaktadır. Bulanık mantık denetim sistemi, genel olarak bulandırma, çıkarım, durulaştırma ve kural tabanı birimi olmak üzere dört temel birimden oluşmaktadır. PI denetleyicinin kazanç parametreleri sabit olduğundan zamanla değişen ve doğrusal olmayan sistemler için başarılı sonuçlar vermemektedir. Uyarlamalı Bulanık-PI denetleyicinin denetim sistemlerinde kullanım amacı, PI kazanç parametrelerinin bulanık mantık denetleyicideki üyelik fonksiyonları ile karakterize edilerek sisteme en uygun PI kazanç parametrelerinin bulunmasıdır [15]. Şekil 4 'de Uyarlamalı Bulanık- PI denetleyici ile senkron motorun güç katsayısı denetim sistemi blok diyagramı verilmiştir. 


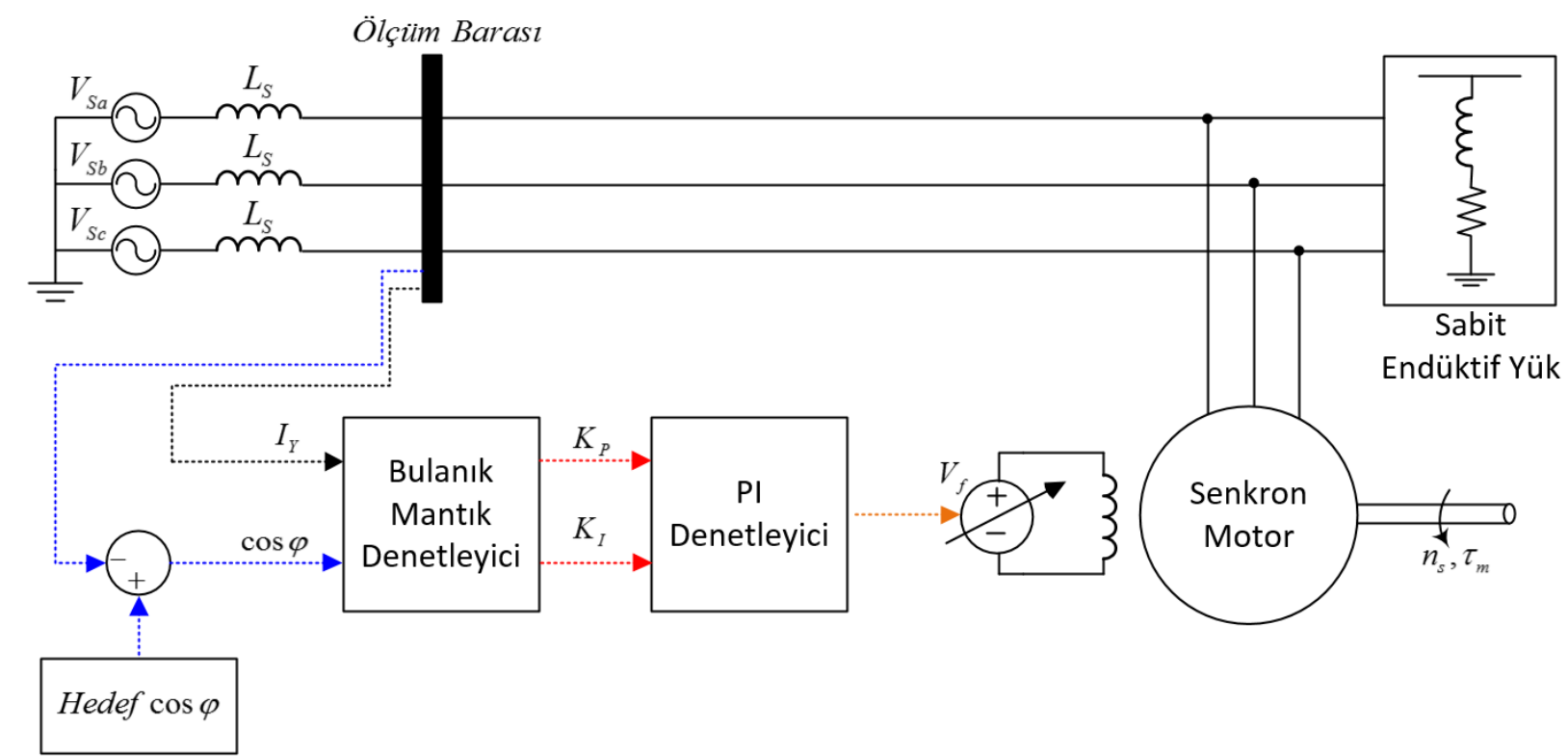

Şekil 4. Uyarlamalı Bulanık PI denetleyici ile senkron motor güç katsayısı denetim sistemi blok diyagramı

Uyarlamalı Bulanık-PI denetleyicide Kp ,Ki kazanç parametreleri için sırasıyla $\left[\mathrm{Kp}_{\min }, \mathrm{Kp}_{\max }\right]$, $\left[\mathrm{Ki}_{\min }, \mathrm{Ki}_{\max }\right]$ minimum ve maksimum değer aralıkları seçilir. Bu değer aralıkları seçilirken PI denetleyici için bulunan Kp, Ki kazanç parametreleri referans alınır. Kp, Ki kazançları için seçilen değer aralıkları eşitlik 3’te aşağıda verilmiştir.

Kp $€$ [5-15],Ki € [0-10]

Kp ve Ki kazanç parametrelerinin hesabı için oluşturulan matematiksel ifade eşitlik 4'de verilmiştir.

$$
\begin{aligned}
& K_{p}^{\prime}=\frac{K_{p}-K_{p \min }}{K_{p \max }-K_{p \min }} \\
& K_{i}^{\prime}=\frac{K_{i}-K_{\mathrm{i} \text { min }}}{K_{\mathrm{i} \max }-K_{\mathrm{i} \min }}
\end{aligned}
$$

Tasarlanan denetleyicide N(Negatif), Z(Sıfır), P(Pozitif) olmak üzere üç dilsel değişken kullanılmıştır. Sisteme verilen her bir giriş için üyelik fonksiyonlarının seçimi tamamen kullanıcının seçimi ile belirlenmekte olup bu çalışmada üçgen ve yamuk üyelik fonksiyonları birlikte kullanılmıştır. Kullanılan üyelik fonksiyonları şekil 5'de verilmiştir.

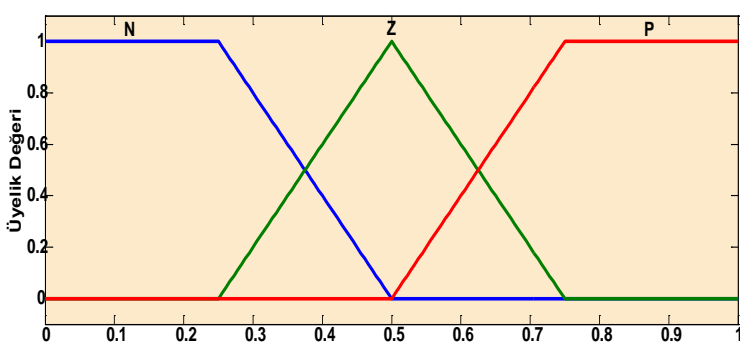

Şekil 5. Uyarlamalı Bulanık PI denetleyici için üyelik fonksiyonları

Güç katsayısı, yük akımı, Kp ve Ki kazanç parametreleri için oluşturulan kural tabanları ise çizelge 1'de verilmiştir.

Çizelge 1. Güç katsayısı, yük akımı, Kp ve Ki için oluşturulan kural tabanları

\begin{tabular}{|c|c|c|c|c|c|c|c|}
\hline \multirow{2}{*}{\multicolumn{2}{|c|}{ Kp/Ki }} & \multicolumn{6}{|c|}{ Iy } \\
\cline { 2 - 8 } & \multicolumn{2}{|c|}{$\mathbf{N}$} & \multicolumn{2}{c|}{$\mathbf{Z}$} & \multicolumn{2}{c|}{$\mathbf{P}$} \\
\hline \multirow{3}{*}{ e } & $\mathbf{N}$ & $\mathbf{N}$ & $\mathbf{P}$ & $\mathbf{N}$ & $\mathbf{P}$ & $\mathbf{N}$ & $\mathbf{Z}$ \\
\cline { 2 - 8 } & $\mathbf{Z}$ & $\mathbf{N}$ & $\mathbf{P}$ & $\mathbf{Z}$ & $\mathbf{Z}$ & $\mathbf{P}$ & $\mathbf{P}$ \\
\cline { 2 - 8 } & $\mathbf{P}$ & $\mathbf{N}$ & $\mathbf{P}$ & $\mathbf{P}$ & $\mathbf{N}$ & $\mathbf{P}$ & $\mathbf{P}$ \\
\hline
\end{tabular}

Aşağıda oluşturulan kurallardan bazıları verilmiştir. Eğer $\mathrm{e}=\mathrm{N}$ ve $\mathrm{Iy}=\mathrm{N}$ ise $\mathrm{O}$ halde $\mathrm{Kp}=\mathrm{N}$ ve $\mathrm{Ki}=\mathrm{P}$ 'dir. Eğer $\mathrm{e}=\mathrm{N}$ ve $\mathrm{Iy}=\mathrm{P}$ ise $\mathrm{O}$ halde $\mathrm{Kp}=\mathrm{N}$ ve $\mathrm{Ki}=\mathrm{Z}$ 'dir. Eğer $\mathrm{e}=\mathrm{P}$ ve $\mathrm{Iy}=\mathrm{P}$ ise $\mathrm{O}$ halde $\mathrm{Kp}=\mathrm{P}$ ve $\mathrm{Ki}=\mathrm{P}$ 'dir.

\section{BENZETIMM ÇALIŞMALARI}

Güç katsayısı elektrik enerjisinin ne kadar verimli kullanıldığını gösteren bir parametredir. Elektrik güç sisteminin güç katsayısı ne kadar büyükse elektrik enerjisi de o oranda verimli kullanılıyor demektir. Bu benzetim çalışmasında dinamik senkron kompanzatör olarak kullanılan senkron motor $8.1 \mathrm{kVA}$ görünür güce ve $400 \mathrm{~V}$ faz-faz aras1 gerilime $1500 \mathrm{~d} /$ dak rotor hızına sahiptir. Kompanzasyonu yapılan endüktif karakterli yük ise 1500 VAR reaktif güce sahiptir. Senkron motorların 
stator sargılarına gerilim uygulandığında ataletlerinden dolayı doğrudan yol alamazlar. Bu yüzden senkron motorlara yol vermek için çeşitli yöntemler vardır. Burada senkron motor asenkron motor gibi çalıştırılarak yol verilmiştir. Senkron motorun rotor hızı şekil 6'da verilmiştir.

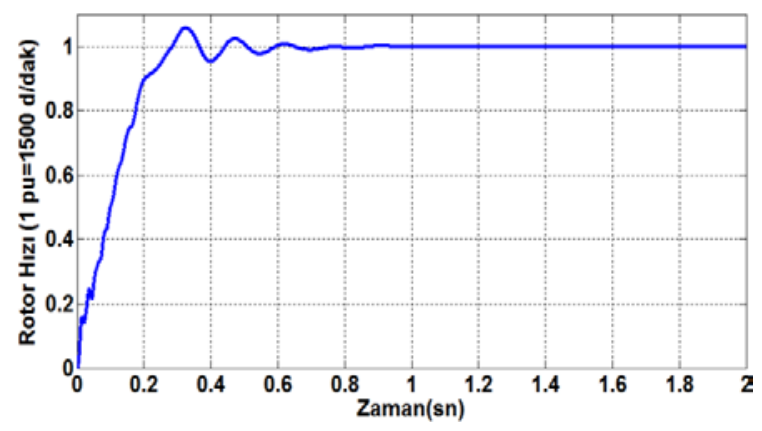

Şekil 6. Senkron motorun rotor hızı

Şekil 6'da görüldüğü gibi senkron motor 0.4 saniye yol aldıktan sonra senkron hıza ulaşmıştır. Sistemin düzeltilen güç katsayısı şekil 7'de verilmiştir.

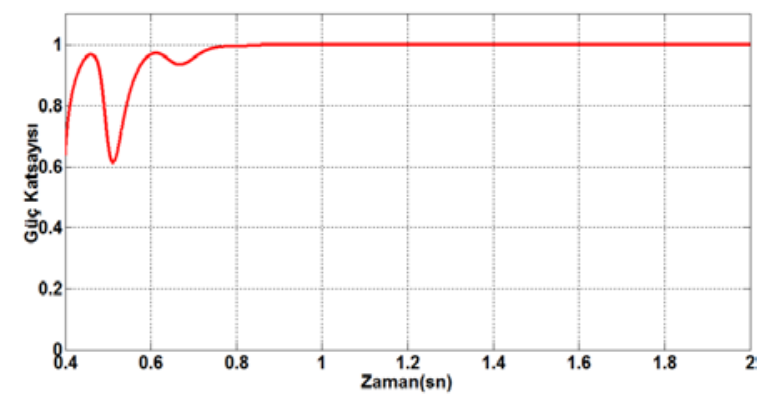

Şekil 7. Sistemin güç katsayısı

Şekil 7'de görüldüğü gibi senkron motor senkron hiza ulaştıktan uyarlamalı bulanık PI denetleyici ile senkron motora \%15 oranında aşırı uyartım akımı verilerek senkron motorun güç sistemine kapasitif karakterde reaktif güç vermesi sağlanmıştır. Böylece senkron motor önce kendini kompanze etmiş ardından da başlangıçta güç katsayısı 0.55 olan sistemin güç katsayısını 1'e yaklaştırmıştır.

\section{SONUÇLAR}

$\mathrm{Bu}$ çalışmada, sabit reaktif güce sahip endüktif yükün reaktif güç kompanzasyonu dinamik kompanzatör olarak kullanılan senkron motor aracılığıyla yapılmıştır. Denetleyici parametrelerinin hesaplanmasinda matematiksel model gereken klasik denetim sistemlerinin yerine sistemi daha hassas hale getirmek ve sistemin verimini artırmak için PI denetleyici parametreleri bulanık mantık denetim yöntemiyle tespit edilmiştir. Uyarlamalı Bulanık-PI esaslı denetim sisteminin çalışması esnasında, güç katsayısı ve yük akımı sürekli olarak gözlenmiştir. Gözlenen bu değerler kural tablosunda değerlendirilmiş ve uyartım akımındaki değişimin sisteme daha etkin bir şekilde uygulanması sağlanmıştır. Bu denetim sistemi kullanılarak yük akımı ihtiyacına göre uyartım akımı daha hassas olacak şekilde ayarlanmıştır. Benzetim çalışması sonuçları incelendiğinde uyarlamalı Bulanık-PI denetleyicinin senkron motor ile güç katsayısı düzeltmede oldukça etkin bir dinamik performansa sahip olduğu görülmüştür.

\section{KAYNAKLAR}

[1]. Bayram M., Kuvvetli Akım Tesislerinde Reaktif Güç Kompanzasyonu, Ağustos 2000, Birsen Yayınevi.

[2]. Mekhamer, S.F., El-Hawary, M.E., Mansour, M.M., Moustafa, M.A., \& Soliman, S.A., "State of the art in optimal capacitor allocation for reactive power compensation in distribution feeders”, IEEE Large Engineering Systems Conference on Power Engineering, LESCOPE 02, 2002, 61-75.

[3]. Bal G., Çolak İ., "Reactive power compensator using constant capacitor and thyristor controlled reactor”, Gazi University, J. of Institute of Science and Technology, vol. 8, No. 2, 1995, p. 915.

[4]. P. W. Sauer, "What is Reactive Power?," Power Systems Engineering Research Center, PSERC Background Paper, Department of Electrical and Computer Engineering, University of Illinois at Urbana-Champaign, September 16, 2003.

[5]. Miller TJE., Reactive Power Control in Electric Systems, October 1982, A Viley-Interscience Publication, New York, p.182-222.

[6]. Al-Hamrani, M.M., Von Jouanne, A., \& Wallace,

[7]. A.,"Power factor correction in industrial facilities using adaptive excitation control of synchronous machines”, Pulp and Paper Industry Technical Conference, Conference Record of the 2002 Annual, 148-154.

[8]. Bayındır R., Sagiroglu S., Colak I, "Yapay sinir ağları tabanlı reaktif güç kompanzasyonu”, Gazi Üniversitesi Teknik Eğitim Fakültesi, Politeknik Dergisi, 2007, 10(2), 129-135.

[9]. Colak I., Bayindir R., Bay O.F.: 'Reactive Power Compensation Using A Fuzzy Logic Controlled Synchronous Motor', Energy Conversion and Management, 2003, 44 (13), 2059-2215.

[10]. Sagiroglu S., Colak I, Bayındır R., "Power Factor Correction Technique Based on Artificial Neural Networks”, Energy Conversion and Management, 2006, Vol. 47/(18-19), 3204-3215.

[11]. Şekkeli M.,"Hassas Bir Reaktif Güç Kompanzasyonu için Gerekli Güçlerin Hesabında Temel Bileşenlerin Kullanılması", KSÜ, Fen ve Mühendislik Dergisi, 2006, 9(2), 66-70.

[12]. http://www.bilgiustam.com/kompanzasyonnedir/ (Erişim Tarihi: 22.12.2015).

[13]. Şekkeli M.,Tarkan M.,"Reaktif güç kontrol rölesinde minimum anahtarlama sayısı ve optimal 
reaktif güç seçimi", İTÜ, İTÜ/d Dergisi, 2005, 4(6), 15-22.

[14]. Bayındır, R. Görgün, A., "PIC Tabanlı Bir PI Denetleyici ile Senkron Motor Kullanılarak Bir Kompanzatör Uygulaması”, Pamukkale Üniversitesi Mühendislik Fakültesi, Mühendislik Bilimleri Dergisi,2009, 15(1), 87-99.

[15]. Çolak İ., Bayındır R., Görgün, A., Kundakoğlu H., "Senkron Motorda Değişik Çalışma Durumlarının Gözlenmesi”, IV. Otomasyon Sempozyumu, 2007, Samsun.

[16]. Şekkeli, M., Açıkgöz H., Gani A., Keçecioğlu Ö.F., "Sürekli Mıknatıslı Senkron Motorların ÖzAyarlamalı Bulanık PID Denetleyici ile Benzetim Çalışması ve Hız Denetimi”, KSÜ,Mühendislik Bilimleri Dergisi,2015, 18(1), 17-22. 